\title{
The interhemispheric fissure-surgical outcome of interhemispheric approaches
}

\author{
A. Kaywan Aftahy ${ }^{1}$ (D) Melanie Barz ${ }^{1} \cdot$ Arthur Wagner $^{1} \cdot$ Friederike Liesche-Starnecker $^{2} \cdot$ Chiara Negwer $^{1}$. \\ Bernhard Meyer ${ }^{1} \cdot$ Jens Gempt ${ }^{1}$
}

Received: 23 May 2020 / Revised: 14 July 2020 / Accepted: 17 August 2020 / Published online: 27 August 2020

(C) The Author(s) 2020

\begin{abstract}
Exposure of the anterior skull base is challenging due to strategic structures. The interhemispheric approach (IHA) has turned out to be a feasible technique. We report our experience with IHAs in patients with extraaxial lesions (EAL). We performed a retrospective chart review at a tertiary neurosurgical center between April 2009 and March 2020. We included patients with resection of EAL through IHAs concentrating on surgical technique, complete resection rate, postoperative outcome, and complications. Seventy-four patients resected by an IHA were included: $49(66.2 \%)$ frontal (FIA), nine (12.1\%) parietooccipital (PIA), and 16 (21.6\%) frontobasal IHAs (FBIAs). Median age at time of surgery was 59 years (range 16-88 years), 47 (63.5\%) female and $27(36.5 \%)$ male. Complete resection rate was $83.8 \%$ (FIA $89.8 \%$, PIA 55.6\%, FBIA $81.3 \%$ ). Rate of new minor deficits was $17.6 \%$, rate of major deficits $5.4 \%$, total rate $23.0 \% .51(68.9 \%) \mathrm{WHO}^{\circ} \mathrm{I}$ meningiomas, ten $(13.5 \%) \mathrm{WHO}^{\circ} \mathrm{II}$ meningiomas, two $(2.7 \%) \mathrm{WHO}^{\circ} \mathrm{III}$ meningiomas, nine $(12.2 \%)$ metastases, one $(1.4 \%)$ sarcoma, and one $(1.4 \%)$ local adenocarcinoma were resected. Total complication rate was $27.0 \%$. Rate of major complications requiring intervention was $9.6 \%$. Mean follow-up was $34.2( \pm 33.2)$ months. In patients with lesions of the interhemispheric fissure, overall morbidity and complications are comparatively high. Extensions of IHAs with potential even higher morbidity are not necessary though; we support the use of standardized IHAs. Our findings suggest regular usage of relatively feasible IHAs for a satisfying outcome. Invasive, complicated, or contralateral trajectories were not needed.
\end{abstract}

Keywords Interhemispheric approach $\cdot$ Meningioma $\cdot$ Neurosurgery $\cdot$ Oncology $\cdot$ Operative technique $\cdot$ Skull base

\section{Introduction}

The frontal interhemispheric approach (FIA) exposes a variety of midline pathologies. Popularized by Ito as the anterior interhemispheric approach (IHA) to reach anterior communicating artery aneurysms [38], the technique became a standardized neurosurgical tool. The anterior dissection exposes, besides interhemispheric structures, pathologies in the suprasellar and prechiasmatic cistern including craniopharyngiomas [19, 20] and midline meningiomas, such as olfactory groove [53],

A. Kaywan Aftahy

kaywan.aftahy@tum.de

1 Department of Neurosurgery, Klinikum rechts der Isar, School of Medicine, Technical University Munich, Ismaninger Str. 22, 81675 Munich, Germany

2 Department of Neuropathology Klinikum rechts der Isar Institute of Pathology School of Medicine, Technical University Munich, Munich, Germany planum sphenoid or tuberculum sellae meningiomas [17, 56, 74]. Access to cingular or callosal lesions through the FIA has also been described [6, 9, 21, 23, 47, 75].

As an alternative, but more as an extension, the frontobasal interhemispheric approach (FBIA) enables the view on the anterior skull base from the crista galli to the tuberculum sellae anteroposteriorly and from the midline to the sphenoid wing bilaterally. The approach has been described as safe, especially in terms of visual and pituitary stalk function $[19,27,64]$. A more subfrontal exposure is allowed.

More posteriorly, the parietooccipital interhemispheric approach (PIA) enables the resection of pathologies in the peritrigonal or periatrial region. This is challenging due to the depth of the region and due to strategically important structures $[12,37,65]$.

The aim of this manuscript is to share our experience with a large series of different IHAs in patients with extra-axial oncologic pathologies at a tertiary neurosurgical university center. With the rise of new but complicated, technically challenging, poorly tested, and therefore potentially harmful 
approaches $[9,12-14,73]$, this study aims to highlight the sufficiency of standardized IHAs and thus the reduction of perioperative morbidity.

\section{Materials and methods}

\section{Study population and clinical parameters}

We performed a noninterventional retrospective single-center study. Between April 2009 and March 2020, we screened the clinical documentation files and neuropathological records of patients who underwent surgery through an IHA for extraaxial tumors.

We analyzed clinical patient files for neurological symptoms, Karnofsky Performance Status Scale (KPSS), postoperative new neurological deficits, postoperative complications, reinterventions, and adverse events according to the Clavien Dindo scale (CDG). Radiological outcome parameters consisted of anatomic location as well as the extent of resection according to postoperative cranial magnetic resonance imaging (MRI) were recorded. We defined the total rate of postoperative new deficits/complications/reinterventions as the number of events divided by the number of patients. Postoperative deficits were defined as minor-to-moderate if they did not cause greater disability, whereas deficits associated with relevant loss of neurological function were defined as major. Deficits were defined as permanent if presented more than 3 months. Postoperative complications were classified in minor or moderate when no urgent intervention was needed and major in cases with subsequent intervention. A return to surgery was defined as an intervention.

We performed statistical analysis using STATA Version 13.1 (2011, StataCorp, College Station, TX). Data are shown as median and interquartile range or as mean and standard deviation; statistical significance was defined as $p<0.05$.

\section{Ethics approval}

The local ethics committee of the Technical University Munich, School of Medicine, approved our study (231/20 SEB). We conducted it in accordance with the ethical standards of the 1964 Declaration of Helsinki and its later amendments [72].

\section{Results}

\section{Study population}

We included 74 patients who underwent surgical resection between April 2009 and March 2020. Median age of our patients at time of surgery was 59 years (range 16-88 years), with $47(63.5 \%)$ female and $27(36.5 \%)$ male patients. Seventeen patients $(23.0 \%)$ had no preoperative symptoms; lesions were discovered incidentally during routine checkups or diagnostic workup for sinusitis or tinnitus. Fifty-seven (77.0\%) patients were symptomatic, including cephalgia, nausea, diplopia, cranial nerve deficits, ataxia/imbalance, and further symptoms. The median preoperative KPSS was $90 \%$ (range 50-90), and the median postoperative KPSS 90\% (range 0-100). Table 1 provides further detailed demographic and clinical information.

\section{Tumor entities, location, and approach-related findings}

Histopathological analysis revealed $51(68.9 \%)$ cases with $\mathrm{WHO}^{\circ} \mathrm{I}$ meningiomas, ten $(13.5 \%)$ WHO II meningiomas, two $(2.7 \%) \mathrm{WHO}^{\circ} \mathrm{III}$ meningiomas, nine $(12.2 \%)$ metastases, one $(1.4 \%)$ sarcoma, and one $(1.4 \%)$ local adenocarcinoma. Table 2 shows all entities and performed approaches in detail. FIA was mostly performed for falcine/parafalcine lesions $(69.4 \%)$ and for lesions at the olfactory groove (22.4\%). PIA was also used most commonly for falcine/parafalcine lesions of the middle or last third of the superior sagittal sinus (55.5\%) but also for metastases in the cingular gyrus. The FBIA was additionally used for technically demanding basal midline meningiomas of the anterior skull base as well as for frontobasal falcine tumors. Table 3 displays the tumor location in relation of the described approaches.

\section{Functional outcome and surgical complications}

Simpson grade I + II resection was achieved in $87.3 \%$ (FIA $93.0 \%$, PIA $50.0 \%$, FBIA $85.7 \%$ ) regarding meningiomas. Complete resection (Simpson grades I + II and GTR) was achieved in $83.8 \%$ of the patients (FIA $89.8 \%$, PIA $55.6 \%$, FBIA $81.3 \%$ ) (Table 3).

Postoperative rate of new permanent minor-to-moderate neurological deficits was $17.6 \%$. Most frequently, hemiparesis was observed in nine patients (12.2\%), followed by psychomotoric disorders in two patients $(2.7 \%)$. New postoperative hemianopsia was observed in one case. Regarding major deficits, postoperative hemiplegia was observed in two $(2.7 \%)$, followed by dysarthria and neglect in one $(1.4 \%)$ patient.

One patient with falcine meningioma of the anterior third of superior sagittal sinus committed suicide postoperatively. In another case with falcine meningioma, resected through a FIA, the ipsilateral pericallosal artery was injured and subsequently sacrificed, leading to a new postoperative permanent hemiparesis.

The overall postoperative complication rate was $27.0 \%$ (FIA $26.5 \%$, PIA $22.2 \%$, FBIA $31.3 \%$ ) The rate of postoperative major complications was $9.6 \%$ The majority of 
Table 1 Demographics and preoperative characteristics

\begin{tabular}{|c|c|c|c|c|}
\hline Demographics $\%(\mathrm{~N})$ or mean/median (SD/IQR) & FIA (49) & PIA (9) & FBIA (16) & Total (74) \\
\hline Age & $61.2( \pm 14,4)$ & $51.6( \pm 16,2)$ & $59( \pm 10)$ & $59( \pm 14)$ \\
\hline Sex & $\begin{array}{l}\text { M } 36.7 \%(18) \\
\text { F } 63.3 \%(31)\end{array}$ & $\begin{array}{l}\text { M } 33.3 \%(3) \\
\text { F } 66.6 \%(6)\end{array}$ & $\begin{array}{l}\text { M } 37.5 \%(6) \\
\text { F } 62.5 \%(10)\end{array}$ & $\begin{array}{l}\text { M } 36.5 \%(27) \\
\text { F } 63.5(47)\end{array}$ \\
\hline \multicolumn{5}{|l|}{ Clinical presentation } \\
\hline Preoperative KPSS & 90 (IQR 80-90) & 90 (IQR 90-100) & 90 (IQR 85-90) & 90 (IQR 50-90) \\
\hline Asymptomatic & $20.4 \%(10)$ & $22.2 \%(2)$ & $31.3 \%(5)$ & $23.0 \%(17)$ \\
\hline Headache & $18.4 \%(9)$ & $33.3 \%(3)$ & $25.0 \%(4)$ & $21.6 \%(16)$ \\
\hline Anosmia & $14.3 \%(7)$ & - & $37.5 \%(6)$ & $17.6 \%(13)$ \\
\hline Vision/visual field deficits & $12.2 \%(6)$ & $11.1 \%(1)$ & $12.5 \%(2)$ & $12.2 \%(9)$ \\
\hline Hemiparesis & $16.3 \%(8)$ & $11.1 \%(1)$ & $6.3 \%(1)$ & $13.5 \%(10)$ \\
\hline Paraparesis & $2.0 \%(1)$ & - & - & $1.4 \%(1)$ \\
\hline Monoparesis & & $11.1 \%(1)$ & - & $1.4 \%(1)$ \\
\hline Hypesthesia/dysesthesia & $4.0 \%(2)$ & $11.1 \%(1)$ & - & $4.1 \%(3)$ \\
\hline Gait/stance disturbance & $6.1 \%(3)$ & $11.1 \%(1)$ & $12.5 \%(2)$ & $8.1 \%(6)$ \\
\hline Seizure & $26.5 \%(13)$ & - & $25.0 \%(4)$ & $23.0 \%(17)$ \\
\hline Psychomotoric disorders & $26.5 \%(13)$ & - & - & $17.6 \%(13)$ \\
\hline Diplopia & $2.0 \%(1)$ & - & $6.3 \%(1)$ & $2.7 \%(2)$ \\
\hline Concentration/memory/cognition impairment & $2.0 \%(1)$ & - & - & $1.4 \%(1)$ \\
\hline Amaurosis fugax & $2.0 \%(1)$ & - & - & $1.4 \%(1)$ \\
\hline Vertigo & $10.2 \%(5)$ & $22.2 \%(2)$ & $25.0 \%$ & $14.9 \%(11)$ \\
\hline Aphasia/dysarthria & $2.0 \%$ & - & - & $1.4 \%(1)$ \\
\hline
\end{tabular}

FBIA, frontobasal interhemispheric approach; FIA, frontal interhemispheric approach; KPSS, Karnofsky Performance Status Scale; PIA, parietooccipital interhemispheric approach

Table 2 Histopathological findings, locations and performed approaches

\begin{tabular}{|c|c|c|c|c|}
\hline Tumor entity \% $(N)$ & FIA (49) & PIA (9) & FBIA (16) & Total (74) \\
\hline Meningioma WHO grade I & $64.7 \%(33)$ & $66.7 \%(6)$ & $75.0 \%(12)$ & $68.9 \%(51)$ \\
\hline Atypic meningioma WHO grade II & $16.3 \%(8)$ & - & $12.5 \%(2)$ & $13.5 \%(10)$ \\
\hline Anaplastic meningioma WHO grade III & $4.1 \%(2)$ & - & - & $2.7 \%(2)$ \\
\hline Metastasis & $10.2 \%(5)$ & $33.3 \%(3)$ & $6.3 \%(1)$ & $12.2 \%(9)$ \\
\hline Sarcoma & $2.0 \%(1)$ & - & & $1.4 \%(1)$ \\
\hline Adenocarcinoma & - & - & $6.3 \%(1)$ & $1.4 \%(1)$ \\
\hline \multicolumn{5}{|l|}{ Tumor location \% $(N)$} \\
\hline Falcine/parafalcine & $69.4 \%(34)$ & $55.5 \%(5)$ & $50.0 \%(8)$ & $63.5 \%(47)$ \\
\hline Olfactory groove & $22.4 \%(11)$ & - & $37.5 \%(6)$ & $23.0 \%(17)$ \\
\hline Planum sphenoidale & - & - & $6.3 \%(1)$ & $1.4 \%(1)$ \\
\hline Frontobasal & - & - & $6.3 \%(1)$ & $1.4 \%(1)$ \\
\hline Tentorial & - & $11.1 \%(1)$ & - & $1.4 \%(1)$ \\
\hline Cingular gyrus & $2.0 \%(1)$ & $11.1 \%(1)$ & - & $2.7 \%(2)$ \\
\hline Central region & $4.1 \%(2)$ & $11.1 \%(1)$ & - & $4.1 \%(3)$ \\
\hline Thalamic & $2.0 \%(1)$ & $11.1 \%(1)$ & - & $2.7 \%(2)$ \\
\hline
\end{tabular}

FBIA, frontobasal interhemispheric approach; FIA, frontal interhemispheric approach; PIA, parietooccipital interhemispheric approach; WHO, World Health Organization 
Table 3 Extent of resection, postoperative presentation and outcome

\begin{tabular}{|c|c|c|c|c|}
\hline $\begin{array}{l}\text { Postoperative presentation } \\
\%(\mathrm{~N})\end{array}$ & FIA (49) & PIA (9) & FBIA (16) & Total (74) \\
\hline $\begin{array}{l}\text { Complete resection (Simpson } \\
\text { I + II + GTR) }\end{array}$ & $89.8 \%$ & $55.6 \%$ & $81.3 \%$ & $83.8 \%$ \\
\hline $\begin{array}{l}\text { EOR in case of other than } \\
\text { meningioma }\end{array}$ & $\begin{array}{l}\text { GTR } 66.6 \%(4 / 6) \\
\text { STR } 33.3 \%(2 / 6)\end{array}$ & $\begin{array}{l}\text { GTR } 66.6 \%(2 / 3) \\
\text { STR } 33.3(1 / 3)\end{array}$ & $\begin{array}{l}\text { GTR } 50 \%(1 / 2) \\
\text { STR } 50 \%(1 / 2)\end{array}$ & $\begin{array}{l}\text { GTR } 63.6 \%(7 / 11) \\
\text { STR } 36.4 \%(4 / 11)\end{array}$ \\
\hline $\begin{array}{l}\text { Simpson grades I-IV in case of } \\
\text { meningioma }\end{array}$ & $\begin{array}{l}\text { I } 58.1 \%(25 / 43) \\
\text { II } 34.9 \%(15 / 43) \\
\text { III } 2.3 \%(1 / 43) \\
\text { IV } 4.7 \%(2 / 43)\end{array}$ & $\begin{array}{l}\text { I } 50.0 \%(3 / 6) \\
\text { III } 16.7 \%(1 / 6) \\
\text { IV } 33.3 \%(2 / 6)\end{array}$ & $\begin{array}{l}\text { I } 35.7 \%(5 / 14) \\
\text { II } 50.0 \%(7 / 14) \\
\text { III } 14.3 \%(2 / 14)\end{array}$ & $\begin{array}{l}\text { I } 52.4 \%(33 / 63) \\
\text { II } 34.9 \%(22 / 63) \\
\text { III } 6.3 \%(4 / 63) \\
\text { IV } 6.3 \%(4 / 63)\end{array}$ \\
\hline Intraoperative complications & $\begin{array}{l}\text { Pericallosal artery injury } \\
\quad 2.0 \% \text { (1) }\end{array}$ & - & MEP decrease $6.25 \%$ (1) & $\begin{array}{l}\text { MEP decrease } 1.4 \%(1) \\
\text { Pericallosal artery injury } \% \\
\quad 1.4 \text { (1) }\end{array}$ \\
\hline \multirow[t]{3}{*}{ Postoperative complications } & $\begin{array}{l}\text { Minor complications } \\
\text { Venous congestion } 6.2 \%(3) \\
\text { Hydrocephalus } 2.0 \% \text { (1) }\end{array}$ & $\begin{array}{l}\text { Minor complications } \\
\text { Venous congestion } \\
11.11 \%(1)\end{array}$ & $\begin{array}{l}\text { Minor complications } \\
\text { WHD } 6.3 \%(1) \\
- \\
-\end{array}$ & $\begin{array}{l}\text { Minor complications } \\
\text { WHD } 1.4 \% \text { (1) } \\
\text { Venous congestion } 5.4 \% \text { (4) } \\
\text { Hydrocephalus } 1.4 \% \text { (1) }\end{array}$ \\
\hline & $\begin{array}{l}\text { Major complications } \\
\text { EDH } 6.2 \%(3) \\
\text { SDH } 2.0 \%(1) \\
\text { ICH } 4.1 \%(2)\end{array}$ & $\begin{array}{l}\text { Major complications } \\
- \\
- \\
-\end{array}$ & $\begin{array}{l}\text { Major complications } \\
- \\
- \\
\text { ICH } 6.3 \% \text { (1) }\end{array}$ & $\begin{array}{l}\text { Major complications } \\
\text { EDH } 4.1 \%(3) \\
\text { SDH } 1.4 \% \text { (1) } \\
\text { ICH } 4.1 \% \text { (3) }\end{array}$ \\
\hline & $\begin{array}{l}\text { During follow-up } \\
\text { Abscess } 6.2 \% \text { (3) }\end{array}$ & $\begin{array}{l}\text { During follow-up } \\
\text { Abscess } 11.1 \% \text { (1) }\end{array}$ & $\begin{array}{l}\text { During follow-up } \\
\text { Abscess } 18.8 \% \text { (3) }\end{array}$ & $\begin{array}{l}\text { During follow-up } \\
\text { Abscess } 9.5 \% \text { (7) }\end{array}$ \\
\hline Postoperative interventions & $\begin{array}{l}\text { Revision due to hemorrhage } \\
8.2 \% \text { (4) } \\
\text { Revision due to infection } \\
\quad 4.1 \% \text { (2) } \\
\text { VP-Shunt } 2.0 \% \text { (1) } \\
\text { Bone explant/implant } 2.0 \% \\
\text { (1) }\end{array}$ & $\begin{array}{l}- \\
- \\
- \\
- \\
\text { Bone explant/implant } \\
\quad 11.1 \%(1)\end{array}$ & $\begin{array}{l}\text { Wound revision } 6.3 \%(1) \\
- \\
- \\
\text { Revision due to infection } \\
\quad 12.5 \% \text { (2) } \\
- \\
\text { Bone explant/implant } 6.3 \% \\
\quad \text { (1) }\end{array}$ & $\begin{array}{l}\text { Wound revision } 2.7 \% \text { (1) } \\
\text { Revision due to hemorrhage } \\
5.4 \% \text { (4) } \\
\text { Revision due to infection } \\
5.4 \% \text { (4) } \\
\text { VP-Shunt } 1.4 \% \text { (1) } \\
\text { Bone explant/implant } 4.1 \% \\
\text { (3) }\end{array}$ \\
\hline \multirow[t]{2}{*}{$\begin{array}{l}\text { New permanent neurological } \\
\text { deficits }\end{array}$} & $\begin{array}{l}\text { Minor deficits } \\
\text { Visual deficits } 2.0 \%(1) \\
\text { Hemiparesis } 12.2 \%(6) \\
\text { Psychomotoric disorders } \\
2.0 \% \text { (1) }\end{array}$ & $\begin{array}{l}\text { Minor deficits } \\
- \\
\text { Hemiparesis } 11.1 \%(2) \\
\text { Paraparesis } 11.1 \%(1) \\
\text { - }\end{array}$ & $\begin{array}{l}\text { Minor deficits } \\
- \\
\text { Hemiparesis } 6.3 \%(1) \\
- \\
\text { Psychomotoric disorders } \\
\quad 6.3 \%(1)\end{array}$ & $\begin{array}{l}\text { Minor deficits } \\
\text { Visual deficits } 1.4 \%(1) \\
\text { Hemiparesis } 12.2 \%(9) \\
\text { Paraparesis } 1.4 \% \text { (1) } \\
\text { Psychomotoric disorders } \\
\quad 2.7 \%(2)\end{array}$ \\
\hline & $\begin{array}{l}\text { Major deficits } \\
\text { Neglect } 2.0 \% \text { (1) } \\
\text { Aphasia/dysarthria } 2.0 \% \text { (1) } \\
\text { Hemiplegia } 2.0 \% \text { (1) }\end{array}$ & $\begin{array}{l}\text { Major deficits } \\
- \\
-\end{array}$ & $\begin{array}{l}\text { Major deficits } \\
- \\
- \\
\text { Hemiplegia } 6.3 \% \text { (1) }\end{array}$ & $\begin{array}{l}\text { Major deficits } \\
\text { Neglect } 1.4 \% \text { (1) } \\
\text { Aphasia/dysarthria 1.4\% (1) } \\
\text { Hemiplegia } 2.7 \% \text { (2) }\end{array}$ \\
\hline Postoperative KPSS & $80 \%(0-90)$ & $90 \%(70-100)$ & $90 \%(80-90)$ & $90 \%(0-100)$ \\
\hline CDG & $\begin{array}{l}\text { I } 59.2 \%(29) \\
\text { II } 18.4 \%(9) \\
\text { IIIa } 6.1 \%(3) \\
\text { IIIb } 12.2 \%(6) \\
\text { IV } 2.0 \%(1) \\
\text { V } 2.0 \%(1)\end{array}$ & $\begin{array}{l}\text { I } 66.6 \%(6) \\
\text { II } 22.2 \%(2) \\
- \\
\text { IIIb } 11.1 \%(1) \\
- \\
-\end{array}$ & $\begin{array}{l}\text { I } 68.8 \%(11) \\
- \\
\text { IIII } 12.5 \%(2) \\
\text { IIIb } 18.8 \%(3) \\
- \\
-\end{array}$ & $\begin{array}{l}\text { I } 62.2 \%(46) \\
\text { II } 14.9 \%(11) \\
\text { IIIa } 6.8 \%(5) \\
\text { IIIb } 13.5 \%(10) \\
\text { IV } 1.4 \%(1) \\
\text { V } 1.4 \%(1)\end{array}$ \\
\hline Follow-up time in months & $33.4( \pm 34.7)$ & $31( \pm 35.7)$ & $38.2( \pm 29.3)$ & $34.2( \pm 33.2)$ \\
\hline
\end{tabular}

$C D G$, Clavien Dindo Scale; $E D H$, epidural hematoma; FBIA, frontobasal interhemispheric approach; FIA, frontal interhemispheric approach; GTR, gross total resection; $I C H$, intracerebral hemorrhage; KPSS, Karnofsky Performance Status Scale; MEP, motor evoked potential; PIA, parietooccipital interhemispheric approach; $S D H$, subdural hematoma; $S T R$, subtotal resection; $V P$, ventriculoperitoneal; $W H D$, wound healing disorder

postoperative hemorrhages/hematomas (epidural hematoma $4.1 \%$, subdural hematoma $1.4 \%$, intracerebral hemorrhage $4.1 \%$ ) with subsequent revision occurred after a FIA (FIA $12.0 \%$, PIA $0.0 \%$, FBIA $6.3 \%$ ). Most common reinterventions were revisions due to hemorrhage or infections in four $(5.4 \%)$ patients, respectively. FBIA developed more postoperative abscesses (FBIA $18.8 \%$, PIA $11.1 \%$, FIA $6.2 \%)$. None of the abscesses $(9.5 \%)$ occurred directly 
postoperative but rather during the first three postoperative months. A revision due to postoperative infection was necessary in $4.1 \%$ of the patients resected by FIA and in $12.5 \%$ of FBIAs (Table 3). Total reintervention rate was $17.6 \%$ (FIA $16.3 \%$, PIA $11.1 \%$, FBIA $25.0 \%$ ). However, no statistical significance could be detected regarding approach-related complications $(p>0.05)$.

Proportionally, postoperative venous congestion occurred in $11.1 \%$ of the patients after a PIA, followed by $6.3 \%$ after a FIA $(p>0.05)$. None of them needed operative reintervention in the postoperative course. Venous congestion, shuntdependent hydrocephalus, and wound healing disorders were classified as moderate or minor complications $(8.1 \%)$ as no immediate return to surgery was needed. (Fig. 1).

The Clavien Dindo Scale for postoperative adverse events showed grade I in $46(62.2 \%)$, grade II in eleven (14.9\%), and grade IIIb in ten $(13.5 \%)$ patients (Table 3). Mean follow-up was $34.2( \pm 33.2)$ months.

\section{Discussion}

Our series showed that the IHA is a technically and comparably safe operative technique. Despite new, but complicated and technically challenging approaches $[9,12-14,73]$, we could achieve complete resection (Simpson grades I + II and GTR) in $83.8 \%$ of our cases (exemplary cases 1-2) with standardized IHAs.

Rate of total new permanent neurological deficits (severe: $5.4 \%$, minor or moderate: $17.6 \%$ ) was $23.0 \%$ (FIA $22.4 \%$, PIA $33.3 \%$, FBIA $18.8 \%$ ), and total complication rate was $27.0 \%$ (FIA $26.5 \%$, PIA $22.2 \%$, FBIA $31.3 \%$ ), satisfactory results compared with the findings of other previous experiences $[5,12,13,18,27,45,56,64,67]$. However, approachrelated obstacles and complications must be taken into consideration when choosing the right approach, anatomic approach-related knowledge is necessary to avoid unnecessary increasing complication rates.

Our findings showed $26.5 \%$ and $22.2 \%$ for FIA and PIA, respectively, which are satisfactory results and are in line within the range of the findings of other authors, such as $24.1 \%$ by Liu et al., $11.5 \%$ by Mielke et al., $22.6 \%$ by Spicer et al., or even $36.5 \%$ by Aryan et al. Actually, in our series, rate of postoperative major complications requiring surgical intervention was $9,6 \%$. Direct comparison with the other findings still remains difficult as others either focused on specific entities, infants or included trauma cases, and vascular lesions [5, 12, 25, 44-46, 48, 67, 74].

For decades, several authors have described alternative approaches to reach, e.g., suprasellar meningiomas or midline lesions of the anterior skull base as an alternative to the IHA.

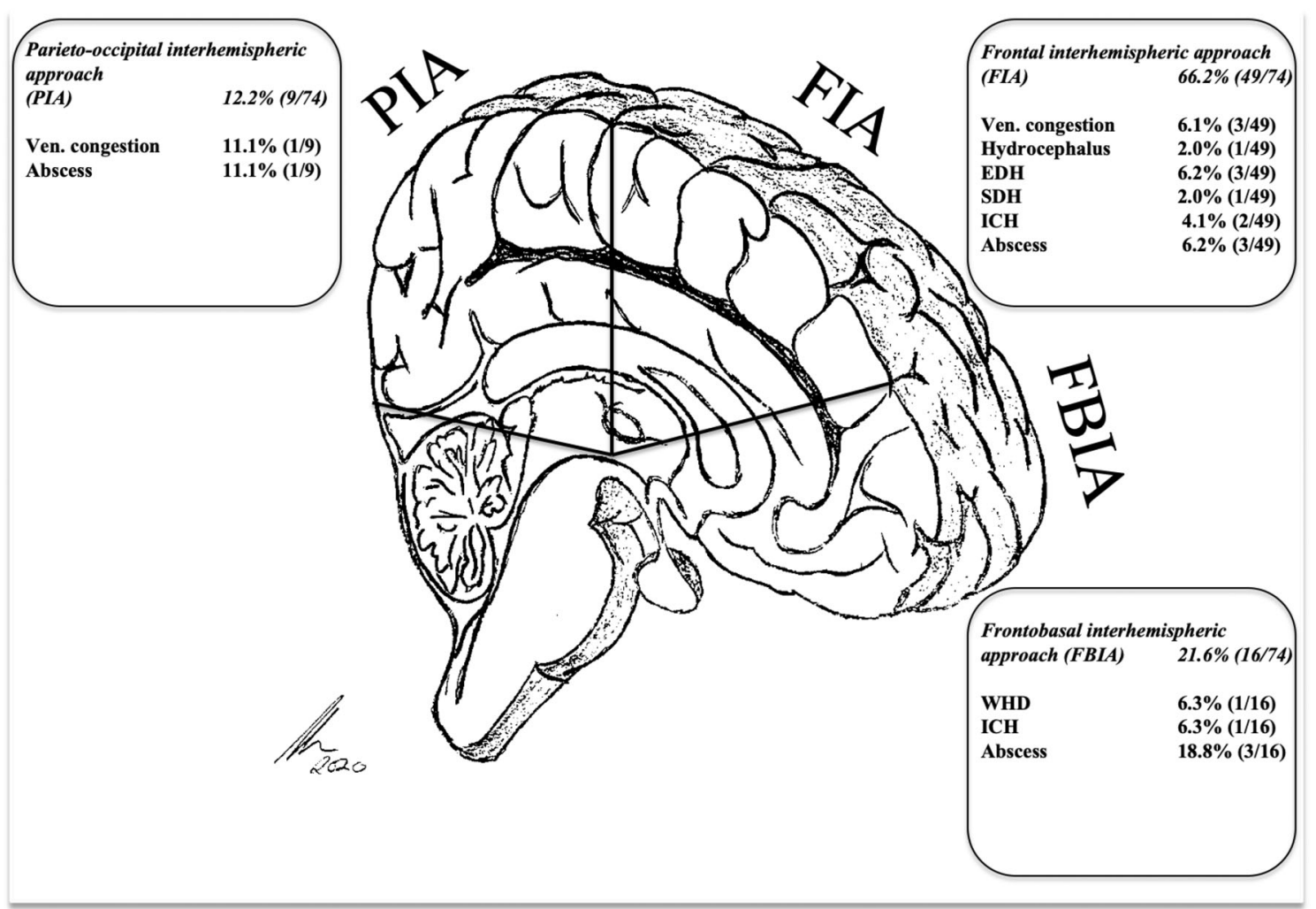

Fig. 1 Approach-related complications \% (N). Abbreviations: WHD, wound healing disorder; EDH, epidural hematoma; SDH, subdural hematoma; ICH, intracerebral hemorrhage 
Median approaches, as presented in current series, might facilitate intraoperative orientation as anatomy is visualized in a straight line. The classic bifrontal approach allows good devascularization, especially in case of frontobasal midline meningiomas $[1,2,8,50,52,56,61,62]$. Still visualization of the anterior communicating complex and optic nerves might be laborious as they are hidden behind the tumor masses which might render this approach less suitable for tuberculum sellae meningiomas $[11,36,40,52]$. The FIA/FBIA might optimize the control of the anterior vascular structures and optic nerves but has been criticized for possible parenchymal retraction $[39,46]$. An adoption from the class bifrontal approach is the transbasal/subfrontal approach, a frontal lobe preserving approach initially described by Cushing [17, 44, 70] which enables superior devascularization with less brain retraction. Wide exposure and unilateral sparing of the contralateral frontal lobe have been described as some of the advantages $[20,24,51,52,56,66]$, but pitfalls of that approach like opening of frontal sinuses and the invasivity with inferior border osteotomies sometimes not being sufficient enough to avoid brain elevation and making neurovascular dissection necessary have let more authors emphasize the advantages of dissecting the interhemispheric fissure for wider exposure. In addition, the risk for CSF leakage might be increased [15, $26,42,52,54-56,60]$. In contrast, other authors advocate more technically demanding transbasal approaches to reach the anterior skull base $[20,24,66]$. Therefore, the FBIA enables a broader anatomical corridor of the interhemispheric fissure that might reduce frontal lobe retraction [19, 20, 27, $56,63,69]$. The FBIA might offer a better visualization if the boney skull base is infiltrated [19, 20, 27, 56, 63, 69]. Nakamura et al. also showed a higher total resection rate (Simpson grade 1 or 2) through a median approach in their series of 82 OGMs: $91.2 \%$ (frontolateral) vs. $93.5 \%$ (bifrontal) [52]; however, they still advocate the less invasive frontolateral approach due to experienced lower morbidity rate and no mortality.

Lateral approaches allow for satisfactory and good visualization of the anterior circulation on both sides as well as superior access to the optic nerve, chiasm, and pituitary complex $[1,11,35,49,52,74]$. The classic pterional and frontolateral approach $[35,61,74]$ offers wide visualization of parenchyma and skull base especially for lesions extending more laterally. As for intradural preparation, meticulous drilling and irrigation is necessary in order to avoid heat related damage to the optic structures $[51,52,54]$. Various modifications of these "working horses" in skull base surgery have been published and trended over recent years $[4,16,32,33$, 57]. Purely endoscopic or endoscopy assisted resections via transnasal or transcranial routes have been popularized for some time offering minimal invasive visualization of the skull base region $[49,59]$. This trend has not peaked into a relevant paradigm shift as extent of resection, technical feasibility, and
CSF leakage rates have been described to be unfavorable compared with classic skull base approaches [7, 41, 49, 59]. Therefore, we do not see any reasonable indication to perform such techniques. Otherwise, if endoscopic approaches had led to any noteworthy advantages, such techniques would have been performed more regularly and spaciously.

However, regarding FIA, we observed postoperative hemorrhages and hematomas as noteworthy complications $(12.0 \%)$. Three epidural, one subdural hematoma, and two intracerebral hemorrhages occurred. Brain retraction as a potential factor for postoperative intracerebral hemorrhages should be consequently reduced as much as possible. Furthermore, the craniotomy and the chosen trajectory should be carefully adapted to the planned approach in order to reduce retraction. Intraoperative meticulous hemostasis as well as closure and usage of tenting sutures, for example, may be taken into consideration as well, especially for the prevention of sub- and epidural hematomas [71, 76]. The FIA remains a suitable approach for large meningiomas of the anterior cranial base, even with involvement of the anterior cerebral arteries into the posterior aspect of the tumor, due to an optimized view from superior-posterior and superior-anterior.

Regarding the PIA, one should notice that crucial vascular structures such as important central bridging veins, the vein of Trolard, and the Rolandic vein are located nearby. Preservation is mandatory during resection, even more than in FIAs, as more of the central region is exposed when more posterity is chosen. Those veins still limit the dural opening of the already narrow working space $[43,58,68]$. We also experienced such difficulties. This complication may be one of the main challenges of the PIA. The importance of preserving bridging veins is not negligible. The study of preoperative MRI to detect prominent bridging or anastomotic veins is essential for sufficient planning.

Major deficits, such as neglect, aphasia, and hemiplegia, respectively, could be considered as a result of exposure of the central region or the parietal lobe, too much brain retraction but also due to damage of frontal and central bridging veins, or ligation of the superior sagittal sinus. Aryan et al. showed that incidence of transient postoperative hemiparesis in infants appeared to be higher in those who required ligation of one or two parasagittal veins ( $44.6 \%$ versus $18.5 \%$ ) in their series of 65 IHA in infants [5] (exemplary case 3 ). Spicer et al. described required coagulation and lysis of bridging cortical veins from the convexity to the sagittal sinus in $41.5 \%$ in their series of 53 cases of IHAs for mass lesions in childhood, which resulted in postoperative hemiparesis in 30\% [67]. Exposure of the superior sagittal sinus is correlated with a better angle of view [3], but also increases the risk of injury of the sinus and the necessity of sacrificing parasagittal/ bridging veins, as seen above, so that especially in the middle and posterior segment the preservation of integrity of the superior sagittal sinus and related bridging veins is of utter 
importance for the postoperative outcome. In cases of postoperative venous congestion, a low-dose heparinization and further change to low-molecular-weight heparin should be taken into consideration. Especially in case of asymptomatic patients, we experienced no need of extensive postoperative heparinization. Recent retro- and prospective studies also showed higher radiographic incidence of postoperative cerebral venous sinus thrombosis than reported in retrospective studies [10, 22, 29, 30]. They also advocated conservative treatment in absence of symptoms; collateral venous drainage is discussed as one of the main mechanisms for well thrombosis tolerance.

To conclude, exposure of superior sagittal sinus, the central region, sacrificing bridging veins, especially parietally, and retraction in case of suboptimal approach and trajectory planning has to be minimized to fully enable the advantage of this comparably cortex sparing technique.

As an extension of the conventional IHA, FBIA can be chosen if the right indication is given and if pathoanatomical conditions require this more extensive approach, such as for large midline meningiomas or craniopharyngiomas $[19,20$, $27,56]$. Primary described by Suzuki et al. as a variation of the bifrontal anterior interhemispheric approach for $3 \mathrm{rd}$ ventricle tumors and anterior communicating artery aneurysms, the FBIA has been extended and modified in the last decades to expose the anterior skull base from a more subfrontal view $[63,69]$. The FBIA has all advantages of the classic anterior subfrontal approach and of the FIA by using the anatomical corridor of the interhemispheric fissure. Frontal lobe retraction can be minimized if the fissure is sufficiently divided. This kind of approach can expose the complete tumor height. Ganna et al. could show satisfactory postoperative outcomes in their series of resected tuberculum sellae meningiomas by FBIA, especially no new visual deficits were observed in their patient cohort, which reflects the outcome of our patient group [27].

Surgically, early identification of the optic apparatus is essential; in most cases, the optic nerves are found displaced posteriorly laterally. After initial tumor debulking further coagulation may be done cautiously as carotid artery often could be placed medial to the displaced optic nerves. Due to already mentioned advantages of exposure and point of view by the FBIA, retraction of the optic nerves is normally not necessary. However, attention must be paid to any arachnoid plane as it serves as a natural layer between the tumor and the neurovascular structures; mobilization and complete tumor

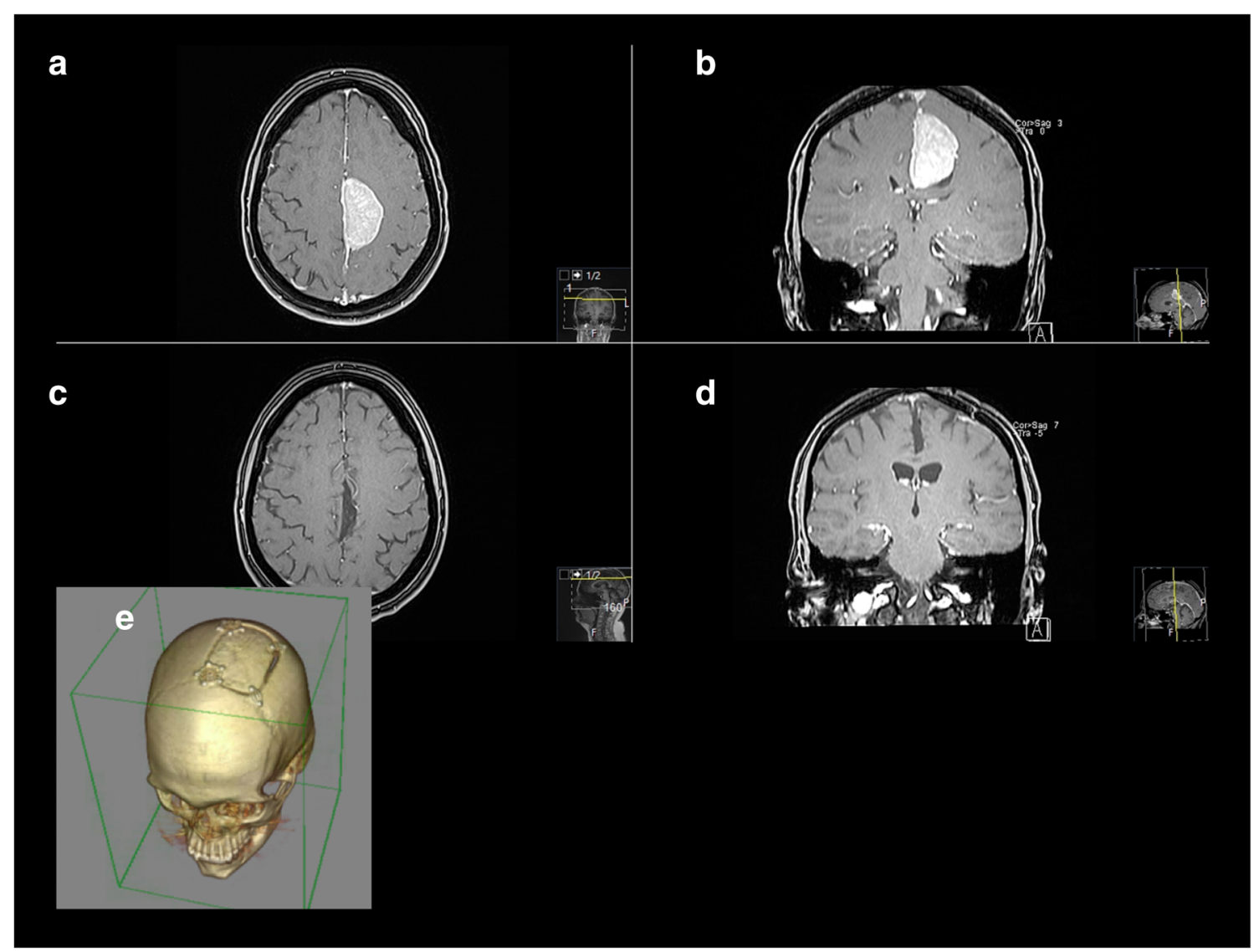

Fig. 2 Exemplary case 1: A 35-year-old female patient presented with depression and seizures. a, b Preoperative T1-weighted gadoliniumenhanced MR imaging showing a left-sided falcine meningioma. c, d
Postoperative MR control showing complete removal, Simpson I. Pathologic findings revealed atypic meningioma WHO grade II. e Postoperative 3D-CT reconstruction showing the bone flap for a FIA 
removal are possible but may be refrained in case of greater adherence in order to maintain visual function. In some cases, the chiasmatic and lamina terminalis cistern has to be exposed more extensively. Afterwards, the anterior communicating complex will come into view and enables more intraoperative control. Unroofing the optic canal and incision of the falciform ligament may be required in case of tumor infiltration into the optic canal and in case of preoperative visual impairment. Such decompression is not mandatory in every case as drilling the optic roof, and the tuberculum sellae may cause additional CSF leak.

To sum it up, we emphasize detailed exposure and wide interhemispheric dissection prior to sometimes too early tumor resection in order to expose, view, and therefore control all necessary structures.

In our series, FBIA is associated with highest approachrelated complication rate (FIA 26.5\%, PIA 22.2\%, FBIA $31.3 \%$ ), most likely caused by the most invasive nature of this technique compared with the others possible frontal sinus opening. On the other hand, FBIA results with least rate of new deficits (FIA 22.4\%, PIA 33.3\%, FBIA 18.8\%).

Regarding complications, cerebrospinal fluid (CSF) leaks are considered the most common ones through such frontobasal techniques, similar to transbasal approaches, especially after dural reconstruction $[15,26]$. However, we experienced no postoperative CSF leak at all, satisfactory results compared with the findings of for example Obeid et al. with $20 \%$ or Raveh et al. and Kurtsoy et al. with $4.8 \%$ and $6.0 \%$, respectively $[42,56,60]$, but one should notice that they referred to more transbasal approaches than we did. The basic surgical technique of the FBIA is already described in detail by other authors before [27, 64]. In fact, we did not use any noteworthy alterations of known techniques, but we advocate regular usage of a navigation system, if applicable, as frontal sinus can be detected preciously and possibly be spared out during craniotomy. We experienced that in some cases, full bony basal exposure is not that mandatory as interhemispheric dissection and the angle of view from anterior to superior or, after new table and microscope positioning, even posteriorsuperior, is satisfactory. Of course, in case of greater lesions with even infiltration of the anterior skull base, full exposure is necessary. In such cases, besides cranialization of the sinus, meticulous dural reconstruction and skull base coverage must be performed, whereas we prioritize priory preparation und usage of a galea-periosteum-flap. We moved away from using fascia lata in the first place as we experienced more CSF leaks

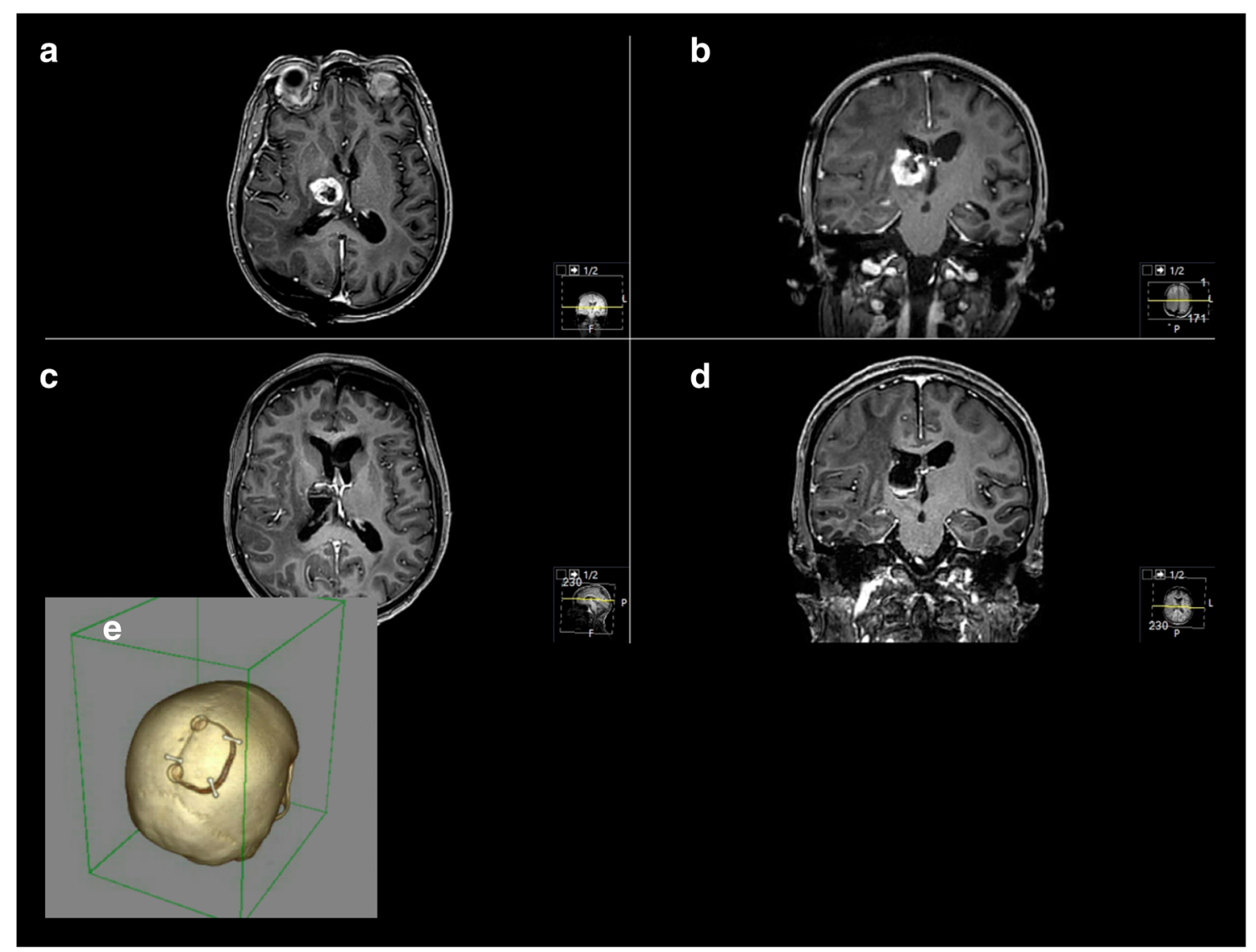

Fig. 3 Exemplary case 2: A 52-year-old female patient presented with paresis. Known breast cancer. a, b Preoperative T1-weighted gadoliniumenhanced MR imaging showing a cystic right thalamic tumor. c, d
Postoperative MR control showing successful resection. Pathologic findings confirmed the metastasis of breast cancer. e Postoperative 3D-CT reconstruction showing the bone flap for a PIA 
than with the flap, which may be based on insufficient vascularization. Necrosis and thus also source of superinfections may be further consequences. However, this just reflects our own institutional experience, whereas techniques of anterior skull base reconstruction have been extensive discussed and algorithms proposed [28, 31, 34].

Anyway, comparison of complication rates is difficult as other authors referred to specific entities, outcome parameters or were small sample sized [20, 27, 45, 64].

Compared with the other approaches, we observed a noteworthy frequency of infection-related complications by FBIA. Incidence of infection is relatively low [15, 26, 28, 45, 60, 62]. They may occur in the case of larger tumors and longer operative times requiring surgical revision with bone flap explantation and plastic flap reconstruction, as with one of our patients (6.3\%). Accidental opening of frontal sinus and consecutive contamination, especially in the case of sinusitis, must be taken into consideration (Figs. 1, 2, 3 and 4). Careful cranialization and sinus obliteration with removal of the mucosa, if needed, should be performed to minimize the postoperative infection rate. In the case of prominent sinus, sinusitis, or other active nasosinal infections, another approach may be considered.

\section{Study limitations}

As it is a retrospective case series, it is not possible to draw causalities with respect to clinical outcome. Nevertheless, we implemented detailed clinical examination, including scores on functional performance, and a standardized follow-up protocol based on a certified neurooncological board into our clinical workflow. Nevertheless, the current study has some noteworthy limitations. Besides of its retrospective nature, the analyzed patient collective suffers from certain aspects of heterogeneity. First, the PIA is limited to 9 on a total of 74 which could lead to variability in the results. We decided to include the PIA into analysis as all aspects of interhemispheric approaches should be reflected and as basic surgical techniques do not differ exceptionally between FIA and PIA.

Secondly, variability of pathologies included could lead to further heterogeneity as majority of cases were meningiomas. With aiming at the approach related complications, we decided to focus on extrinsic lesions, as manipulation techniques seemed to be more similar, so complications could be reduced on the approaches as good as possible.

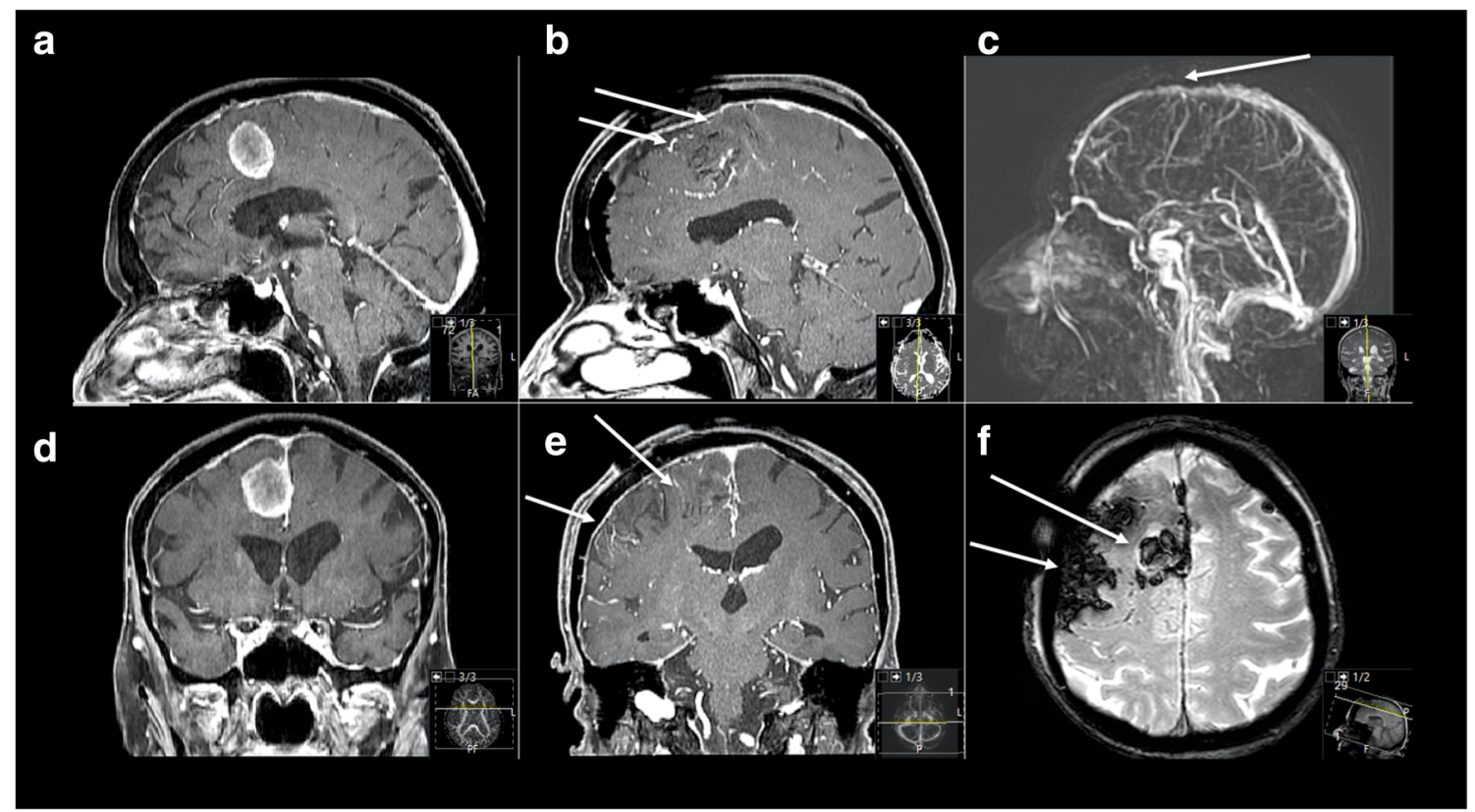

Fig. 4 Exemplary case 3: A 75-year-old female patient presented with slight progressive headache, psychomotoric decline, vertigo, and subjective weakness of left lower limb. a, b Preoperative T1-weighted gadolinium-enhanced MR imaging showing a right-sided falcine meningioma with maximal diameter of $2.4 \mathrm{~cm}$. A FIA was performed. $\mathbf{c}, \mathbf{d}$ Postoperative MR control showing successful resection, but with new right frontal parenchymal hemorrhage as well as bleeding into the resection cavity. Increased vessel drawing in the sulci as indirect sign of postoperative venous congestion (arrows) can be seen. e Postoperative dynamic MR angiography reconstruction showing no obvious bridging or sinus vein thrombosis, but certain constriction is visible (arrow). $\mathbf{f}$ Multiecho gradient recalled echo (GRE) T2*-weighted imaging showing typical hemorrhage configurations with accompanying visible vessels along the sulci and gyral edema (arrows). Postoperatively, the patient suffered from deteriorated psychomotoric decline and new left-sided lower limb pronounced hemiparesis which did not recover completely during follow-up. However, walking and daily activities were possible in further course 


\section{Conclusions}

In patients with lesions of the interhemispheric fissure, overall morbidity and complications are comparatively high. Modifications or extensions of IHAS with a potential even higher morbidity are not necessary; we support the use of standardized IHAs for a variety of entities. Our findings suggest regular usage of relatively feasible IHAs for a satisfying outcome and maximal extent of resection. Invasive, complicated, or contralateral trajectories were not needed.

Availability of data and material Data and material are not publicly available.

Authors' contributions Conceptualization: A. Kaywan Aftahy; Methodology: A. Kaywan Aftahy, Melanie Barz; Formal analysis and investigation: A. Kaywan Aftahy, Melanie Barz; Writing - original draft preparation: A. Kaywan Aftahy; Writing - review and editing: Melanie Barz, Arthur Wagner, Friederike Liesche-Starnecker, Chiara Negwer, Bernhard Meyer, Jens Gempt; Supervision: Chiara Negwer, Bernhard Meyer, Jens Gempt.

Funding Information Open Access funding provided by Projekt DEAL.

\section{Compliance with ethical standards}

Conflict of interest Jens Gempt (JG) and Bernhard Meyer (BM) work as consultants for Brainlab (Brainlab AG, Feldkirchen).

In addition, BM works as a consultant for Medtronic, Spineart, Icotec, Relievant, and Depuy/Synthes. In these firms, BM acts as a member of the advisory board. Furthermore, BM reports a financial relationship with Medtronic, Ulrich Medical, Brainlab, Spineart, Icotec, Relievant, and Depuy/Synthes. He received personal fees and research grants for clinical studies from Medtronic, Ulrich Medical, Brainlab, Icotec, and Relievant. All this happened independently of the submitted work. BM holds the royalties/patent for Spineart. All named potential conflicts of interest are unrelated to this study. There are no further conflicts of interest regarding the other authors.

Ethics approval The local ethics committee of the Technical University Munich, School of Medicine, approved our study (231/20 S-EB). We conducted it in accordance with the ethical standards of the 1964 Declaration of Helsinki and its later amendments [72].

Informed consent The requirement for written informed consent was waived by the ethics committee.

\section{Code availability Not applicable.}

Open Access This article is licensed under a Creative Commons Attribution 4.0 International License, which permits use, sharing, adaptation, distribution and reproduction in any medium or format, as long as you give appropriate credit to the original author(s) and the source, provide a link to the Creative Commons licence, and indicate if changes were made. The images or other third party material in this article are included in the article's Creative Commons licence, unless indicated otherwise in a credit line to the material. If material is not included in the article's Creative Commons licence and your intended use is not permitted by statutory regulation or exceeds the permitted use, you will need to obtain permission directly from the copyright holder. To view a copy of this licence, visit http://creativecommons.org/licenses/by/4.0/.

\section{References}

1. Aguiar PH, Tahara A, Almeida AN, Simm R, Silva AN, Maldaun MV, Panagopoulos AT, Zicarelli CA, Silva PG (2009) Olfactory groove meningiomas: approaches and complications. J Clin Neurosci 16:1168-1173. https://doi.org/10.1016/j.jocn.2008.12. 013

2. Al-Mefty O, Holoubi A, Rifai A, Fox JL (1985) Microsurgical removal of suprasellar meningiomas. Neurosurgery 16:364-372. https://doi.org/10.1227/00006123-198503000-00014

3. Alvernia JE, Lanzino G, Melgar M, Sindou MP, Mertens P (2009) Is exposure of the superior sagittal sinus necessary in the interhemispheric approach? Neurosurgery 65:962-965. https://doi.org/10. 1227/01.Neu.0000349210.98919.88

4. Arai H, Sato K, Okuda, Miyajima M, Hishii M, Nakanishi H, Ishii H (2000) Transcranial transsphenoidal approach for tuberculum sellae meningiomas. Acta Neurochir 142:751-756; discussion 756-757. https://doi.org/10.1007/s007010070089

5. Aryan HE, Ozgur BM, Jandial R, Levy ML (2006) Complications of interhemispheric transcallosal approach in children: review of 15 years experience. Clin Neurol Neurosurg 108:790-793. https://doi. org/10.1016/j.clineuro.2005.10.009

6. Asgari S, Engelhorn T, Brondics A, Sandalcioglu IE, Stolke D (2003) Transcortical or transcallosal approach to ventricleassociated lesions: a clinical study on the prognostic role of surgical approach. Neurosurg Rev 26:192-197. https://doi.org/10.1007/ s10143-002-0239-4

7. Banu MA, Mehta A, Ottenhausen M, Fraser JF, Patel KS, Szentirmai O, Anand VK, Tsiouris AJ, Schwartz TH (2016) Endoscope-assisted endonasal versus supraorbital keyhole resection of olfactory groove meningiomas: comparison and combination of 2 minimally invasive approaches. J Neurosurg 124:605620. https://doi.org/10.3171/2015.1.JNS141884

8. Bassiouni H, Asgari S, Stolke D (2007) Olfactory groove meningiomas: functional outcome in a series treated microsurgically. Acta Neurochir 149:109-121; discussion 121. https://doi.org/10.1007/ s00701-006-1075-z

9. Belykh E, Yagmurlu K, Lei T, Safavi-Abbasi S, Oppenlander ME, Martirosyan NL, Byvaltsev VA, Spetzler RF, Nakaji P, Preul MC (2018) Quantitative anatomical comparison of the ipsilateral and contralateral interhemispheric transcallosal approaches to the lateral ventricle. J Neurosurg 128:1492-1502. https://doi.org/10.3171/ 2017.1.JNS161338

10. Benjamin CG, Sen RD, Golfinos JG, Sen C, Roland JT, McMenomey S, Pacione D (2018) Postoperative cerebral venous sinus thrombosis in the setting of surgery adjacent to the major dural venous sinuses. J Neurosurg 131:1317-1323. https://doi. org/10.3171/2018.4.Jns 18308

11. Bitter AD, Stavrinou LC, Ntoulias G, Petridis AK, Dukagjin M, Scholz M, Hassler W (2013) The role of the pterional approach in the surgical treatment of olfactory groove meningiomas: a 20-year experience. J Neurol Surg B Skull Base 74:97-102. https://doi.org/ 10.1055/s-0033-1333618

12. Bradley NB, Charles GK, Mitesh VS, Aaron AC-G (2015) Posterior interhemispheric transfalcine transprecuneus approach for microsurgical resection of periatrial lesions: indications, technique, and outcomes. J Neurosurg 123:1045-1054. https://doi.org/ 10.3171/2015.3.JNS14847

13. Burkhardt JK, et al. (2018). Contralateral posterior interhemispheric approach to deep medial parietooccipital vascular malformations: surgical technique and results. J Neurosurg 129(1):198-204.

14. Chaddad-Neto F, Devanir Silva da Costa M, Bozkurt B, Leonardo Doria-Netto H, de Araujo Paz D, da Silva Centeno R, Grande AW, Cavalheiro S, Yagmurlu K, Spetzler RF, Preul MC (2018) Contralateral anterior interhemispheric-transcallosal-transrostral 
approach to the subcallosal region: a novel surgical technique. $\mathrm{J}$ Neurosurg 129:508-514. https://doi.org/10.3171/2017.4. JNS16951

15. Chandler JP, Silva FE (2005) Extended transbasal approach to skull base tumors. Technical nuances and review of the literature. Oncology (Williston Park) 19:913-919 discussion 920, 923-915, 929

16. Chokyu I, Goto T, Ishibashi K, Nagata T, Ohata K (2011) Bilateral subfrontal approach for tuberculum sellae meningiomas in longterm postoperative visual outcome. J Neurosurg 115:802-810. https://doi.org/10.3171/2011.5.Jns101812

17. Curey S, Derrey S, Hannequin P, Hannequin D, Freger P, Muraine M, Castel H, Proust F (2012) Validation of the superior interhemispheric approach for tuberculum sellae meningioma: clinical article. J Neurosurg 117:1013-1021. https://doi.org/10.3171/2012.9. JNS12167

18. Dehdashti AR, de Tribolet N (2005) Frontobasal Interhemispheric trans-lamina terminalis approach for suprasellar lesions. Neurosurgery 56:ONS-418-ONS-424. https://doi.org/10.1227/01. Neu.0000157027.80293.C7

19. Dehdashti AR, de Tribolet N (2005) Frontobasal interhemispheric trans-lamina terminalis approach for suprasellar lesions. Neurosurgery 56:418-424; discussion 418-424. https://doi.org/10. 1227/01.neu.0000157027.80293.c7

20. Dehdashti AR, de Tribolet N (2008) Frontobasal interhemispheric trans-lamina terminalis approach for suprasellar lesions. Neurosurgery 62:1233-1239. https://doi.org/10.1227/01.neu. $0000333789.90972 .8 \mathrm{f}$

21. Ehni G (1984) Interhemispheric and percallosal (transcallosal) approach to the cingulate gyri, intraventricular shunt tubes, and certain deeply placed brain lesions. Neurosurgery 14:99-110. https://doi. org/10.1227/00006123-198401000-00023

22. Eisenring CV, Neidert MC, Sabanés Bové D, Held L, Sarnthein J, Krayenbühl N (2013) Reduction of thromboembolic events in meningioma surgery: a cohort study of 724 consecutive patients. PLoS One 8:e79170-e79170. https://doi.org/10.1371/journal.pone. 0079170

23. Ellenbogen RG. Transcortical surgery for lateral ventricular tumors. Neurosurg Focus 10(6):E2. https://doi.org/10.3171/foc.2001.10.6.3

24. Feiz-Erfan I, Spetzler RF, Horn EM, Porter RW, Beals SP, Lettieri SC, Joganic EF, Demonte F (2008) Proposed classification for the transbasal approach and its modifications. Skull Base 18:29-47. https://doi.org/10.1055/s-2007-994292

25. Feng S-Y, Zhou T, Sun Z-H, Bu B, Jiang J-L (2018) Anterior interhemispheric approach for removing large sellar region tumor. Medicine 97:e10840. https://doi.org/10.1097/MD. 0000000000010840

26. Fliss DM, Zucker G, Cohen A, Amir A, Sagi A, Rosenberg L, Leiberman A, Gatot A, Reichenthal E (1999) Early outcome and complications of the extended subcranial approach to the anterior skull base. Laryngoscope 109:153-160. https://doi.org/10.1097/ 00005537-199901000-00029

27. Ganna A, Dehdashti AR, Karabatsou K, Gentili F (2009) Frontobasal interhemispheric approach for tuberculum sellae meningiomas; long-term visual outcome. Br J Neurosurg 23:422-430. https://doi.org/10.1080/02688690902968836

28. Georgantopoulou A, Hodgkinson PD, Gerber CJ (2003) Cranialbase surgery: a reconstructive algorithm. Br J Plast Surg 56:10-13. https://doi.org/10.1016/s0007-1226(03)00013-4

29. Gerber DE, Segal JB, Salhotra A, Olivi A, Grossman SA, Streiff MB (2007) Venous thromboembolism occurs infrequently in meningioma patients receiving combined modality prophylaxis. Cancer 109:300-305. https://doi.org/10.1002/cncr.22405

30. Gerlach R, Raabe A, Scharrer I, Meixensberger J, Seifert V (2004) Post-operative hematoma after surgery for intracranial meningiomas: causes, avoidable risk factors and clinical outcome. Neurol Res 26:61-66. https://doi.org/10.1179/ 016164104773026543

31. Gil Z, Abergel A, Leider-Trejo L, Khafif A, Margalit N, Amir A, Gur E, Fliss DM (2007) A comprehensive algorithm for anterior skull base reconstruction after oncological resections. Skull Base 17:25-37. https://doi.org/10.1055/s-2006-959333

32. Goel A, Bhaganagare A, Shah A, Kaswa A, Rai S, Dharurkar P, Gore S (2018) Olfactory groove meningiomas: an analysis based on surgical experience with 129 cases. Neurol India 66:1081-1086. https://doi.org/10.4103/0028-3886.236989

33. Goel A, Muzumdar D, Desai KI (2002) Tuberculum sellae meningioma: a report on management on the basis of a surgical experience with 70 patients. Neurosurgery 51:1358-1363 discussion 1363-1354

34. Gök A, Erkutlu I, Alptekin M, Kanlikama M (2004) Three-layer reconstruction with fascia lata and vascularized pericranium for anterior skull base defects. Acta Neurochir 146:53-56; discussion 56-57. https://doi.org/10.1007/s00701-003-0175-2

35. Hassler W, Zentner J (1989) Pterional approach for surgical treatment of olfactory groove meningiomas. Neurosurgery 25:942-947. https://doi.org/10.1227/00006123-198912000-00014

36. Hassler W, Zentner J (1989) Pterional approach for surgical treatment of olfactory groove meningiomas. Neurosurgery 25:942-945 discussion 945-947

37. Ito H, Morino M, Niimura M, Takamizawa S, Shimizu Y (2015) Posterior callosotomy using a parietooccipital interhemispheric approach in the semi-prone park-bench position. J Neurosurg 123: 1322-1325. https://doi.org/10.3171/2014.12.Jns141732

38. Ito Z (1982) The microsurgical anterior interhemispheric approach suitably applied to ruptured aneurysms of the anterior communicating artery in the acute stage. Acta Neurochir 63:85-99. https://doi. org/10.1007/bf01728859

39. Joseph V, Chacko AG (2005) Suprabrow minicraniotomy for suprasellar tumours. Br J Neurosurg 19:33-37. https://doi.org/10. 1080/02688690500089415

40. Kempe LG, VanderArk GD (1971) Anterior communicating artery aneurysms. Gyrus rectus approach. Neurochirurgia (Stuttg) 14:6370. https://doi.org/10.1055/s-0028-1090556

41. Komotar RJ, Starke RM, Raper DM, Anand VK, Schwartz TH (2012) Endoscopic endonasal versus open transcranial resection of anterior midline skull base meningiomas. World Neurosurg 77: 713-724. https://doi.org/10.1016/j.wneu.2011.08.025

42. Kurtsoy A, Menkü A, Tucer B, Oktem I, Akdemir H, Koç R (2004) Transbasal approaches: surgical details, pitfalls and avoidances. Neurosurg Rev 27:267-273. https://doi.org/10.1007/s10143-0040322-0

43. Kyoshima K, Oikawa S, Kobayashi S (2001) Preservation of large bridging veins of the cranial base: technical note. Neurosurgery 48: 447-449. https://doi.org/10.1097/00006123-200102000-00047

44. Leveque S, Derrey S, Martinaud O, Gerardin E, Langlois O, Freger P, Hannequin D, Castel H, Proust F (2011) Superior interhemispheric approach for midline meningioma from the anterior cranial base. Neurochirurgie 57:105-113. https://doi.org/10.1016/j.neuchi. 2011.08.001

45. Liu JK, Silva NA, Sevak IA, Eloy JA (2018) Transbasal versus endoscopic endonasal versus combined approaches for olfactory groove meningiomas: importance of approach selection. Neurosurg Focus 44:E8. https://doi.org/10.3171/2018.1. FOCUS17722

46. Lu ZF (2014) Resection of suprasellar meningioma through interhemispheric approach. J Craniofac Surg 25:1302-1304. https://doi. org/10.1097/scs.0000000000000771

47. Mazza M, Di Rienzo A, Costagliola C, Roncone R, Casacchia M, Ricci A, Galzio RJ (2004) The interhemispheric transcallosaltransversal approach to the lesions of the anterior and middle third 
ventricle: surgical validity and neuropsychological evaluation of the outcome. Brain Cogn 55:525-534. https://doi.org/10.1016/j.bandc. 2004.03.005

48. Mielke D, Mayfrank L, Psychogios MN, Rohde V (2014) The anterior interhemispheric approach: a safe and effective approach to anterior skull base lesions. Acta Neurochir 156:689-696. https:// doi.org/10.1007/s00701-013-1972-x

49. Mortazavi MM, Brito da Silva H, Ferreira M Jr, Barber JK, Pridgeon JS, Sekhar LN (2016) Planum sphenoidale and tuberculum sellae meningiomas: operative nuances of a modern surgical technique with outcome and proposal of a new classification system. World Neurosurg 86:270-286. https://doi.org/10. 1016/j.wneu.2015.09.043

50. Mukherjee S, Thakur B, Corns R, Connor S, Bhangoo R, Ashkan $\mathrm{K}$, Gullan R (2015) Resection of olfactory groove meningioma - a review of complications and prognostic factors. Br J Neurosurg 29: 685-692. https://doi.org/10.3109/02688697.2015.1054348

51. Nakamura M, Roser F, Struck M, Vorkapic P, Samii M (2006) Tuberculum sellae meningiomas: clinical outcome considering different surgical approaches. Neurosurgery 59:1019-1028; discussion 1028-1019. https://doi.org/10.1227/01.NEU.0000245600. 92322.06

52. Nakamura M, Struck M, Roser F, Vorkapic P, Samii M (2007) Olfactory groove meningiomas: clinical outcome and recurrence rates after tumor removal through the frontolateral and bifrontal approach. Neurosurgery 60:844-852; discussion 844-852. https:// doi.org/10.1227/01.NEU.0000255453.20602.80

53. Nakamura M, Struck M, Roser F, Vorkapic P, Samii M (2008) Olfactory groove meningiomas: clinical outcome and recurrence rates after tumor removal through the frontolateral and bifrontal approach. Neurosurgery 62:1224-1232. https://doi.org/10.1227/ 01.neu.0000333788.83349.1e

54. Nanda A, Maiti TK, Bir SC, Konar SK, Guthikonda B (2016) Olfactory groove meningiomas: comparison of extent of frontal lobe changes after lateral and bifrontal approaches. World Neurosurg 94:211-221. https://doi.org/10.1016/j.wneu.2016.06. 101

55. Nanda A, Patra DP, Savardekar AR, Mohammed N, Narayan V, Bir SC (2018) Surgery of tuberculum sellae meningioma: a technical purview on pterional approach. J Neurol Surg B Skull Base 79: S265-S266. https://doi.org/10.1055/s-0038-1625945

56. Obeid F, Al-Mefty O (2003) Recurrence of olfactory groove meningiomas. Neurosurgery 53:534-542; discussion 542-533. https:// doi.org/10.1227/01.neu.0000079484.19821.4a

57. Ohta K, Yasuo K, Morikawa M, Nagashima T, Tamaki N (2001) Treatment of tuberculum sellae meningiomas:a long-term followup study. J Clin Neurosci 8(Suppl 1):26-31. https://doi.org/10. 1054/jocn.2001.0873

58. Otani N, Wada K, Toyooka T, Mori K (2018) Occipital interhemispheric approach for surgical removal of the middle third falx meningioma: two case reports. Asian J Neurosurg 13:789-791. https:// doi.org/10.4103/ajns.AJNS_158_16

59. Ottenhausen M, Rumalla K, Alalade AF, Nair P, Corte EL, Younus I, Forbes JA, Nsir AB, Banu MA, Tsiouris AJ, Schwartz TH (2018) Decision-making algorithm for minimally invasive approaches to anterior skull base meningiomas. Neurosurg Focus 44:E7. https:// doi.org/10.3171/2018.1.Focus17734

60. Raveh J, Turk JB, Ladrach K, Seiler R, Godoy N, Chen J, Paladino J, Virag M, Leibinger K (1995) Extended anterior subcranial approach for skull base tumors: long-term results. J Neurosurg 82: 1002-1010. https://doi.org/10.3171/jns.1995.82.6.1002

61. Schick U, Hassler W (2005) Surgical management of tuberculum sellae meningiomas: involvement of the optic canal and visual outcome. J Neurol Neurosurg Psychiatry 76:977-983. https://doi.org/ 10.1136/jnnp.2004.039974
62. Sekhar LN, Nanda A, Sen CN, Snyderman CN, Janecka IP (1992) The extended frontal approach to tumors of the anterior, middle, and posterior skull base. J Neurosurg 76:198-206. https://doi.org/ 10.3171/jns.1992.76.2.0198

63. Shibuya M, Takayasu M, Suzuki Y, Saito K, Sugita K (1996) Bifrontal basal interhemispheric approach to craniopharyngioma resection with or without division of the anterior communicating artery. J Neurosurg 84:951-956. https://doi.org/10.3171/jns.1996. 84.6.0951

64. Shirane R, Hayashi T, Tominaga T (2005) Fronto-basal interhemispheric approach for craniopharyngiomas extending outside the suprasellar cistern. Childs Nerv Syst 21:669-678. https://doi.org/ 10.1007/s00381-005-1206-5

65. Sorenson J, Khan N, Couldwell W, Robertson J (2016) The Rhoton collection. World Neurosurg 92:649-652. https://doi.org/10.1016/j. wneu.2016.06.037

66. Spektor S, Valarezo J, Fliss DM, Gil Z, Cohen J, Goldman J, Umansky F (2005) Olfactory groove meningiomas from neurosurgical and ear, nose, and throat perspectives: approaches, techniques, and outcomes. Neurosurgery 57:268-280; discussion 268-280. https://doi.org/10.1227/01.neu.0000176409.70668.eb

67. Spicer M, McComb JG, Levy ML (2001) 838 complications of interhemispheric transcallosal approaches for mass lesions in childhood. Neurosurgery 49:547-547. https://doi.org/10.1097/ 00006123-200108000-00202

68. Sugita K, Kobayashi S, Takemae T, Matsuo K, Yokoo A (1980) Direct retraction method in aneurysm surgery. Technical note. $\mathrm{J}$ Neurosurg 53:417-419. https://doi.org/10.3171/jns.1980.53.3. 0417

69. Suzuki J, Mizoi K, Yoshimoto T (1986) Bifrontal interhemispheric approach to aneurysms of the anterior communicating artery. $\mathrm{J}$ Neurosurg 64:183-190. https://doi.org/10.3171/jns.1986.64.2. 0183

70. Symon L, Rosenstein J (1984) Surgical management of suprasellar meningioma. Part 1: the influence of tumor size, duration of symptoms, and microsurgery on surgical outcome in 101 consecutive cases. J Neurosurg 61:633-641. https://doi.org/10.3171/jns.1984. 61.4.0633

71. Winston KR (1999) Efficacy of dural tenting sutures. J Neurosurg 91:180-184. https://doi.org/10.3171/jns.1999.91.2.0180

72. (2013) World Medical Association Declaration of Helsinki: ethical principles for medical research involving human subjects. JAMA 310:2191-2194. https://doi.org/10.1001/jama.2013.281053

73. Yagmurlu K, Zaidi HA, Kalani MYS, Rhoton AL, Preul MC, Spetzler RF (2018) Anterior interhemispheric transsplenial approach to pineal region tumors: anatomical study and illustrative case. J Neurosurg 128:182-192. https://doi.org/10.3171/2016.9. JNS16279

74. Yaşargil MG (1996) Microneurosurgery: microsurgery of CNS tumors: instrumentation and equipment, laboratory, training, surgical approaches, strategies, tactics and techniques, surgery and results of extrinsic and intrinsic tumors, interventional neuroradiology, neuroanesthesia, Complications. Thieme,

75. Yasargil MG, Abdulrauf SI (2008) Surgery of intraventricular tumors. Neurosurgery 62:1029-1040; discussion 1040-1021. https:// doi.org/10.1227/01.neu.0000333768.12951.9a

76. Zhao J, Liu Z, Liu Y, Liu J, Fang W, Rao Y, Yang L, Yuan X (2010) Effect of epidural drainage and dural tenting suture on epidural hematoma in 145 cases of craniotomy. Zhong Nan Da Xue Xue Bao Yi Xue Ban 35:273-276

Publisher's note Springer Nature remains neutral with regard to jurisdictional claims in published maps and institutional affiliations. 